\title{
Exposure and injury risk in Swedish elite football: a comparison between seasons 1982 and 2001
}

Martin Hägglund, Markus Waldén and Jan Ekstrand

Linköping University Post Print

\section{Tweet}

N.B.: When citing this work, cite the original article.

Original Publication:

Martin Hägglund, Markus Waldén and Jan Ekstrand, Exposure and injury risk in Swedish elite football: a comparison between seasons 1982 and 2001, 2003, Scandinavian Journal of Medicine and Science in Sports, (13), 6, 364-370.

http://dx.doi.org/10.1046/j.1600-0838.2003.00327.x

Copyright: BLACKWELL MUNKSGAARD 2003

http://onlinelibrary.wiley.com/

Postprint available at: Linköping University Electronic Press

http://urn.kb.se/resolve?urn=urn:nbn:se:liu:diva-14339 


\title{
Exposure and Injury Risk in Swedish Elite
}

\section{Football: A Comparison between Seasons 1982}

\author{
and 2001.
}

Martin Hägglund PT

Markus Waldén MD

Jan Ekstrand MD, PhD

From the Department of Social Medicine and Public Health Science, Linköping University, Linköping, Sweden.

Key words: sports injuries; soccer injuries; incidence; epidemiology, prospective study.

Address for correspondence:

Martin Hägglund PT, Sports Clinic, Solstigen 3, S-58943 Linköping, Sweden.

Tel: +46 13 140991. Fax: +46 13 351112. E-mail: hagglund.martin@telia.com 


\section{ABSTRACT}

The long-term development of injury risk in Swedish male elite football was studied. Two prospective cohort studies from seasons 1982 and 2001 were compared regarding exposure to football, injury incidence and injury severity.

The mean number of training sessions during the season had increased by $68 \%$ between 1982 and 2001 (142 vs. 238, p<0.001), whereas teams played more matches in 1982 (49 vs. 41, $\mathrm{p}=0.02$ ). The total exposure to football had increased by $27 \%$. Three out of four players incurred an injury in both seasons. In 2001, players suffered more training injuries due to an increased training exposure. Accounting for risk exposure, there was no difference in injury incidence or severity between the two seasons. The incidence was 8,3 injuries/1000 hours of total exposure (4,6 in training and 20,6 in matches) in 1982 , compared to $7,8 / 1000$ hours $(5,2$ in training and 25,9 in matches) in 2001. Major injuries accounted for nine per cent of all injuries, corresponding to an incidence of $0,8 / 1000$ hours of football, in both seasons. A trend from semi-professionalism to full professionalism in Swedish elite football was seen during the last two decades. The injury risk did not change over the same period. 


\section{INTRODUCTION}

Injuries in football have been the subject of increasing interest, and several studies have been published during the last two decades regarding the injury patterns in football. (Inklaar, 1994; Dvorak \& Junge, 2000) The incidence of football injuries in adult male players is estimated to be 1,5 to 7,6 per 1000 hours of training and 12 to 35 per 1000 hours of matches. (Dvorak \& Junge, 2000)

Factors that may influence the incidence of injury in football include the level of play, exercise load (i.e. number of training sessions and matches) and the standard of training. The risk for injury during matches has been reported to be higher amongst high-level players than low-level players (Nielsen \& Yde, 1989; Ekstrand \& Tropp, 1990; Inklaar et al., 1996), whereas in training the outcome appears to be the opposite (Nielsen \& Yde, 1989; Ekstrand \& Tropp, 1990).

Several authors have investigated the frequency of injuries in elite football. (Lewin, 1989; Engström et al., 1990; Árnason et al., 1996; Lüthje et al., 1996; Hawkins \& Fuller, 1998; 1999; Hawkins et al., 2001) From these studies it is clear that elite players run a great risk for injury, with between 65 (Lüthje et al., 1996) and 91\% (Lewin, 1989) of the players incurring an injury during one season.

Football has become more and more popular over the last two decades, and the game is constantly developing with increasing speed and intensity. Still, little is known about the development of injury risk during the same period. Due to methodological differences between studies it is difficult to draw any conclusions as to the change in injury risk in 
football with time. One previous study on elite ice hockey players in Finland showed an increase in the risk for injury during matches from the 1970s to the 1990s (Mölsä et al., 2000). To our knowledge, the long-term development of injury risk in football has not been studied. The purpose of this study was to compare exposure, injury incidence and injury severity in Swedish male elite football between seasons 1982 and 2001. 


\section{MATERIALS AND METHODS}

\section{Data collection}

1982

Using a cohort study design, all teams $(\mathrm{N}=12)$ in the Swedish top division (highest domestic level of competition) were followed throughout the football season (January to October) in 1982. The design was the same as that used previously by Ekstrand (1982) on male amateurs. Before the start of the study, each team coach selected 15 players (first team) to participate in the study, giving a total of 180 players. The mean (SD) age of the participating players was $25,5(3,4)$ years (range 19-35 years). Attendance at all training sessions and matches was recorded on a special form by each team. Training and matches with the national team as well as second or youth teams were included. Each training session and match was estimated as 90 minutes exposure. All injuries that occurred during the study period were registered on the attendance forms. No information regarding the type or location of injuries was recorded.

2001

Using the same cohort study design, all teams $(\mathrm{N}=14)$ in the Swedish top division were investigated during the football season (January - October) of 2001. All first team players in the squad during the first study month (January) were included in the study; players joining the teams after January were not included. Players who were already injured at the start of the study were included but their present injuries were not taken into account. All players were informed about the study by their team doctor, and signed informed consent obtained. Three hundred and ten of 312 players in the 14 clubs accepted participation (range 18-25 players/team). The mean (SD) age of the 310 players was $24,9(4,7)$ years (range 17-38 years). 
Each team kept attendance records for all training sessions and matches on special forms. The actual exposure to football (training and matches separately) was recorded in minutes for each player. Training and matches with the second or youth team, as well as national teams, were included. A training session was defined as any coach-directed scheduled physical activity carried out with the team.

All injuries that occurred during the study period were recorded on a special injury card. The injury card provided information on the date of injury, scheduled activity (i.e. training or match), type, location, whether it was a re-injury (an identical injury of the same type and location within two months of the final rehabilitation day of the previous injury), if the injury was caused by a foul (according to the referee), and whether it was a traumatic or overuse injury. An overuse injury was defined according to Orava (1980, p.13) as "a pain syndrome of the musculoskeletal system appearing during physical exercise without any known trauma, disease, deformity or anomaly that might have given previous symptoms".

Attendance records and injury cards were sent in to the authors each month during the study period. The information was checked through newspapers and official team web sites for mismatching data.

After the season, each team coach in the study 2001 retrospectively selected the " 15 best players" from the total squad for additional analyses. The coaches were asked to select the 15 players that they considered to be the first team before the start of the season in January 2001, irrespective of the players' actual performance or injuries during the season. 


\section{Injury definition and severity}

The same injury definition was used in both seasons. An injury was defined according to Ekstrand (1982) as any injury occurring during scheduled training sessions or matches causing the player to miss the next training session or match. The club medical staff (consisting of doctor and physiotherapist/naprapath) diagnosed all injuries. An injured player was considered injured until the club medical staff cleared him for participation in full training or matches. Players who performed alternative training were considered as injured. Injuries were classified into four categories of severity according to the length of absence from training sessions and matches: slight (1-3 days), minor (4-7 days), moderate (8-28 days) and major (>28 days), including the day of injury.

\section{Exclusions and dropouts}

Exclusions and dropouts are presented in Table 1. In 1982, four teams failed to provide complete data for the full study period and were excluded from the analyses. A further two players, who joined their teams after January, were excluded. A total of 62 out of the 180 players $(34 \%)$ were excluded. Three players $(2,5 \%)$ dropped out during the study period due to change of clubs. All 14 teams in the study 2001 sent in complete data for the full study period. Thirty-one players (10\%) dropped out during the study period, 28 due to club transfers, two were degraded to the youth team and one player stopped playing football due to disease. Data from players who dropped out during the study are included in the analyses for their entire time of participation.

\section{Calculation of exposure and injury incidence}

The mean number of training sessions and matches were calculated at team level as well as for the individual player. The value for each season represents the mean number of training 
sessions and first team matches that the teams or the players had during that season. Exposure to football was calculated for each player as described previously. Each value represents the mean for all the players each season. Match exposure was sometimes corrected in the study 1982 so that the combined exposure for all the players in one team did not exceed 990 minutes for one match (i.e. 11 players x 90 minutes). If, for example, 12 players in one team were registered as participating in the same match (11 players + one substitute), each player was given 82,5 minutes of exposure (i.e. 990/12).

Injury incidence was calculated as all injuries per 1000 hours of football (training + matches), as well as for injuries per 1000 hours of training and matches separately. This was done at team level (i.e. (the number of injuries per team/hours of exposure per team) x 1000), the reported value representing the mean for each season.

\section{Statistical analyses}

Data was statistically analysed using StatView ${ }^{\circledR}$ version 5.0.1 (SAS Institute Inc.). Groups were compared with the chi-square test for qualitative variables. Quantitative variables were compared between groups using Student's t-test or the Mann-Whitney U-test in case of heterogeneity of variance between groups (F-ratio test), or a non-normal distribution (Kolmogorov-Smirnov test). (Armitage \& Berry, 1994) The significance level was set at $\mathrm{p} \leq 0.05$. Results are reported as mean with standard deviations (SD) and $95 \%$ confidence interval $(95 \% \mathrm{CI})$.

The study was approved by the Ethics Committee of the University of Linköping, Sweden. 


\section{RESULTS}

All analyses referred to in the text are comparisons between season $1982(\mathrm{~N}=118)$ and the full squad in season $2001(\mathrm{~N}=310)$. Additional analyses of season 1982 compared to the 15 best players in 2001 are presented in Tables 2-4.

\section{Exposure}

Table 2 displays the exposure to football for seasons 1982 and 2001. In 2001, the teams had more training sessions from January to October (238 vs. 142, p<0.001), whereas in 1982 the teams played more matches (first team) on average ( 49 vs. $41, \mathrm{p}=0.02$ ). The training/match ratio (i.e. number of training sessions/number of matches) doubled from 1982 to 2001. In 1982, the teams had 3,0 (SD 0,4) training sessions per match compared to 5,9 $(0,7)$ per match in $2001(\mathrm{p}<0.001)$. On average, each player participated in 119 training sessions and 41 matches in 1982. The corresponding values were 183 training sessions and 29 matches per player in 2001. The total exposure to football in hours increased by $27 \%$ from 1982 to 2001 $(\mathrm{p}<0.001)$, due to an increase in the amount of training.

\section{Number and severity of injuries}

In 1982, 90 players (76\%) incurred 236 injuries, of which 99 (42\%) occurred during training and 137 (58\%) during matches. In 2001, 238 players (77\%) incurred 715 injuries, 421 (59\%) during training and $294(41 \%)$ during matches. Table 3 shows the injury distribution according to severity. The majority of injuries were slight or minor injuries $(67 \%$ and $60 \%$ for 1982 and 2001 respectively) causing an absence of one week or less. Nine per cent of the injuries resulted in an absence of over 28 days (major injuries). The mean (SD) number of 
days of absence per injury was 11,6 (23,5) (range 1-229 days) and 13,8 (33,2) (range 1-361 days) days for 1982 and 2001 respectively $(\mathrm{p}=0.34)$.

\section{Injury incidence}

The injury incidences are shown in Table 4. In 1982, the individual player incurred 2,0 injuries during the season ( 0,8 in training and 1,2 in matches). Similarly, there were 2,3 injuries/player/season in 2001 (1,4 in training and 0,9 in matches). Players in 2001 suffered more training injuries during the season $(\mathrm{p}=0.008)$. Taking exposure to football into account, there was no difference in injury incidence between the two seasons. There were 8,3 injuries/1000 hours of total exposure in 1982 (4,6 in training and 20,6 in matches) compared to 7,8 injuries/1000 hours of total exposure (5,2 in training and 25,9 in matches) in 2001 . The injury incidences for slight, minor, moderate and major injuries separately did not differ between the seasons. 


\section{DISCUSSION}

The principal finding of this study was that there was no difference in injury risk between seasons 1982 and 2001. This was the first study with the aim to evaluate the long-term development of exposure and injury risk in football. One problem with epidemiological studies on injuries in football is the different methodology used. There is no consensus about the definition of injury, and differences in data collection make comparisons between studies difficult. It has therefore not been possible to study time trends in the risk for injury in football.

The investigations were carried out prospectively with a cohort study design. The same injury definition was used in both seasons, i.e. an injury incurring during football activity causing absence from at least one training session or match. This time lost definition has previously been applied in several studies on injuries in football (Ekstrand et al., 1983a; Lewin, 1989; Nielsen \& Yde, 1989; Engström et al., 1990; Árnason et al., 1996; Hawkins \& Fuller, 1999). However, the time lost from sport definition has recently been criticized (Dvorak \& Junge, 2000). Absence from training sessions and matches is influenced by a subjective component, as well as other factors such as the importance of the player or the match, the frequency of training sessions and matches etc. A "tissue damage" definition based on the prevalence of complaints due to football, and not only absence, has therefore been suggested by Junge \& Dvorak (2000). There is probably no ideal definition, and the time lost criterion has been recommended for studies of football injuries since it takes into account those injuries that are most likely to affect the player's health and performance (Keller et al., 1987). 
A few methodological issues are important to acknowledge. In the study 1982, each team coach selected the 15 best players to participate in the study prior to the start of the season. This selection may be a potential bias regarding the exposure to matches, and consequently the risk for injury, as these players are likely to participate in first team matches to a high extent. Previous studies have indicated that the injury risk during matches is greater the higher level of play (Nielsen \& Yde, 1989; Ekstrand \& Tropp, 1990; Inklaar et al., 1996). In the season 2001, some players participated mainly in second team matches and only in a few first team matches, which may influence match exposure and the risk for injury. However, additional analyses with the 15 best players in the season 2001 compared to the season 1982 gave similar results. The inclusion of all first team players, as in the season 2001, is preferable to a selection of the " 15 best players" in each team, as this sample does not represent the true population at risk. The selection of specific players for participation in a study may affect the injury incidence as the behaviour of the player influences the risk for injury (Junge, 2000).

The lower stringency of data collection in 1982, with an estimation of 90 minutes exposure for each training session and match, is another potential bias regarding the players' actual exposure to football and, thus, the risk for injury. The estimation does not account for players that are sent off from matches, or do not attend the entire training session. True exposure may therefore be less than that reported, which might have led to an underestimation of the injury risk in 1982. Training sessions in the season 2001 lasted 87 minutes on average (i.e. 264 hours of training exposure per player/183 training sessions per player), indicating that the estimation of 90 minutes per training session used in 1982 is a valid assumption. Nevertheless, it is important to know the actual amount of time each player is at risk for injuring himself to be able to analyse the true risk for injury. We therefore recommend the procedure used in the 
study 2001, with the actual exposure being recorded individually, for future studies on injury risk in football.

We found an increase in exposure between 1982 and 2001 reflecting a development from semi-professionalism to full professionalism in Swedish elite football. In 1982, the teams had 142 training sessions during the season on average, compared to 238 in 2001, an increase of $68 \%$. On the contrary, the teams had more matches on average in 1982, 49 matches compared to 41 in 2001 . The lower number of matches played in 2001 is partly due to the fact that the teams in the study 1982 participated in a national indoor tournament at the beginning of the year. In 2001 this tournament no longer existed. Consequently, there was no significant difference in the number of matches played during the season if the month of January is excluded.

A large percentage of the players incurred one or more injuries during the season (76 and $77 \%$ for 1982 and 2001). This is in accordance with previous studies, in which 65 to $91 \%$ of the players were injured (Lewin, 1989; Engström et al., 1990; Árnason et al., 1996; Lüthje et al., 1996). In the season 1982, two out of three injuries were match injuries, and one-third were training injuries, whereas in 2001 the outcome was the reverse. This was due to the different amounts of time spent in training and matches between the two seasons. In 1982, each player had 182 hours of training and 55 hours of match exposure, compared to 264 hours of training and 37 hours of match exposure in 2001. This emphasizes the importance of accounting for exposure when estimating injury risk in football, as the actual time that players are at risk for injury influences the number of injuries that occur. 
Due to an increased training exposure, players in 2001 suffered more training injuries during the season. However, accounting for risk exposure, there was no difference in injury incidence, with 8,3 and 7,8 injuries per 1000 hours of total risk exposure for 1982 and 2001 respectively. In a previous study on Swedish semi-professional players, Engström et al. (1990) found a lower total incidence of 5 injuries per 1000 hours ( 3 in training and 13 in matches). This difference could possibly be explained by the smaller study sample (three teams) in that study. Icelandic elite football players were found to have a higher incidence during matches $(34,8 / 1000$ hours $)$, whereas the incidence during training was similar $(5,9)$ to the present study (Árnason et al., 1996). The authors attributed the high injury incidence during matches to the short season in Iceland, allocating only short time for rest and recuperation between matches. Hawkins \& Fuller (1999) reported a similar total incidence of 8,5 injuries per 1000 hours (3,4 and 25,9 in training and matches respectively) for English professional footballers.

The high intensity and the tight schedule of training sessions and matches are factors that may contribute to the high injury incidence in elite football. (Engström et al., 1990; Árnason et al., 1996) We found an increase in overall risk exposure between 1982 and 2001 that was not associated with an increase in injury incidence. It thus seems that an increase in overall risk exposure does not lead to an increased injury incidence in football, provided it is the amount of training that increases. This would suggest that the recommendation by Ekstrand et al. (1983a) that a high training/match ratio is beneficial is also valid in elite football. Indeed, the training/match ratio was twice as high in 2001 as in 1982. However, it is feasible that the introduction of preventive measures in Swedish elite football during the last two decades has evened out the possible negative effects of an increase in overall exposure. With the tight schedule in elite football today, trainers and medical staff should ensure a proper 
training/match relationship and consider implementation of alternative training and recovery time between sessions in order to avoid injuries due to physical (and mental) overload.

The injuries observed in this study were predominantly slight or minor injuries. Major injuries accounted for nine per cent of all injuries in both seasons. This is in the lower range of what has previously been reported in elite football (11 to 34\%) from studies with similar injury severity classification. (Engström et al., 1990; Lüthje et al., 1996; Hawkins \& Fuller, 1999; Hawkins et al., 2001) The definition of injury severity used in this study (i.e. the number of days of absence from training or matches) is dependent on the frequency of training sessions and matches. A lower frequency could result in the time of injuries being reported as a few days shorter than they would have been had the schedule been tighter. This could possibly explain the difference in the distribution of injuries according to severity between the seasons 1982 and 2001 in this study.

Unfortunately, no information regarding the nature of the injuries that occurred in 1982 was collected. It is therefore not possible to conclude whether the type and location of injuries have changed between 1982 and 2001.

The findings of this study on the development of injury risk in football are in contrast to one previous study on ice hockey. Mölsä et al. (2000) reported an 52\% increase in the risk for injury during matches for elite ice hockey players in Finland from the 1970s to the 1990s. The authors attributed this to an increase in rough body contact between players. 


\section{Conclusions}

This was the first study to evaluate the long-term development of exposure and injury risk in football. A trend from semi-professionalism to full professionalism in Swedish elite football was seen between 1982 and 2001. A large increase in the amount of training was found, whereas the number of matches played had decreased slightly. Elite football players run a great risk for injury, with three out of four players incurring an injury during one season. The injury risk has not changed over the last twenty years.

\section{Perspectives}

Several studies have been published during the last two decades regarding injuries in football, and preventive measures that may be taken. However, prospective randomised intervention studies are scarcer. In a Swedish study on male amateurs, Ekstrand et al. (1983b) showed that injury rates could successfully be decreased with a prevention program. Since then, a few intervention studies have been carried out in men's football (Surve et al., 1994; Caraffa et al., 1996), and more recently in women's (Heidt et al., 2000; Söderman et al., 2000) and youth football (Junge et al., 2002). The present study shows that elite football players in Sweden run a similar risk for injuring themselves today as they did twenty years ago. Hence, there is a need for further investigation on how to reduce the incidence and severity of injuries in elite football. Furthermore, knowledge is still lacking as to whether the type and mechanisms of injury has changed with time. This aspect should be addressed in future studies. 


\section{Acknowledgements}

The authors wish to thank the participating clubs, coaches, medical staff and players. The statistical advice from Nadine Karlsson and language corrections from Peter Cox is gratefully acknowledged. This study was supported by grants from the Swedish Sports Confederation (Sports Research Council) and the Swedish Football Association. 


\section{REFERENCES}

Armitage P, Berry G. Statistical methods in medical research. 3rd ed. Oxford: Blackwell, 1994.

Árnason Á, Gudmundsson Á, Dahl HA, Jóhansson E. Soccer injuries in Iceland. Scand J Med Sci Sports 1996: 6: 40-45.

Caraffa A, Cerulli G, Projetti M, Aisa G, Rizzo A. Prevention of anterior cruciate ligament injuries in soccer. A prospective controlled study of proprioceptive training. Knee Surg Sports Traumatol Arthroscopy 1996: 4: 19-21.

Dvorak J, Junge A. Football injuries and physical symptoms: A review of the literature. Am J Sports Med 2000: 28 (Suppl.): S3-S9.

Ekstrand J. Soccer injuries and their prevention. Linköping University Medical Dissertations, No 130, Sweden, 1982.

Ekstrand J, Gillquist J, Möller M, Öberg B, Liljedahl SO. Incidence of soccer injuries and their relation to training and team success. Am J Sports Med 1983a: 11: 63-67.

Ekstrand J, Gillquist J, Liljedahl SO. Prevention of soccer injuries. Supervision by doctor and physiotherapist. Am J Sports Med 1983b: 11 (3): 116-120.

Ekstrand J, Tropp H. The incidence of ankle sprains in soccer. Foot \& Ankle 1990: 11 (1): 4144.

Engström B, Forssblad M, Johansson C, Törnkvist H. Does a major knee injury definitely sideline an elite soccer player? Am J Sports Med 1990: 18 (1): 101-105.

Hawkins RD, Fuller CW. An examination of the frequency and severity of injuries and incidents at three levels of professional football. Br J Sports Med 1998: 32: 326-332.

Hawkins RD, Fuller CW. A prospective epidemiological study of injuries in four English professional football clubs. Br J Sports Med 1999: 33: 196-203. 
Hawkins RD, Hulse MA, Wilkinson C, Hodson A, Gibson M. The association football medical research programme: an audit of injuries in professional football. Br J Sports Med 2001: 35: 43-47.

Heidt RS, Sweeterman LM, Carlonas RL, Traub JA, Tekulve FX. Avoidance of soccer injuries with preseason conditioning. Am J Sports Med 2000: 28 (5): 659-662.

Inklaar H. Soccer injuries. I: Incidence and severity. Sports Med 1994: 18 (1): 55-73.

Inklaar H, Bol E, Schmikli SL, Mosterd WL. Injuries in male soccer players: team risk analysis. Int J Sports Med 1996: 17 (3): 229-234.

Junge A. The influence of psychological factors on sports injuries. Am J Sports Med 2000: 28 (Suppl.): S10-S15.

Junge A, Dvorak J. Influence of definition and data collection on the incidence of injuries in football. Am J Sports Med 2000: 28 (Suppl.): S40-S46.

Junge A, Rösch D, Peterson L, Graf-Baumann T, Dvorak J. Prevention of soccer injuries: a prospective intervention study in youth amateur players. Am J Sports Med 2002: 30 (5): 652-659.

Keller CS, Noyes FR, Buncher RC. The medical aspects of soccer injury epidemiology. Am J Sports Med 1987: 15 (3): 230-237.

Lewin G. The incidence of injury in an English professional soccer club during one competitive season. Physiother 1989: 75 (10): 601-605.

Lüthje P, Nurmi I, Kataja M, Belt E, Helenius P, Kaukonen JP, Kiviluoto H, Kokko E, Lehtipuu TP, Lehtonen A, Liukkonen T, Myllyniemi J, Rasilainen P, Tolvanen E, Virtanen H, Walldén M. Epidemiology and traumatology of injuries in elite soccer: a prospective study in Finland. Scand J Med Sci Sports 1996: 6: 180-185.

Mölsä J, Kujala U, Näsman O, Lehtipuu T-P, Airaksinen O. Injury profile in ice hockey from the 1970s through the 1990s in Finland. Am J Sports Med 2000: 28 (3): 322-327. 
Nielsen AB, Yde J. Epidemiology and traumatology of injuries in soccer. Am J Sports Med 1989: 17 (6): 803-807.

Orava S. Exertion injuries due to sports and physical exercise. A clinical and statistical study of nontraumatic overuse injuries of the musculoskeletal system of athletes and keep-fit athletes. Thesis, University of Oulu, Finland, 1980.

Surve I, Schwellnus MP, Noakes T, Lombard C. A fivefold reduction in the incidence of recurrent ankle sprains in soccer players using the sport-stirrup orthosis. Am J Sports Med 1994: 22 (5): 601-605.

Söderman K, Werner S, Pietilä T, Engström B, Alfredson H. Balance board training: prevention of traumatic injuries of the lower extremities in female soccer players? Knee Surg Sports Traumatol Arthrosc 2000: 8: 356-363. 


\section{FIGURES AND LEGENDS}

Table 1

Exclusions and dropouts.

\section{Table 2}

Number of training sessions and matches, and exposure to football, in seasons 1982 and 2001.

Means with standard deviations (SD) and 95\%

confidence interval $(95 \% \mathrm{CI})$.

\section{Table 3}

Severity of injuries according to absence from training sessions and matches in seasons 1982 and 2001 .

Table 4

Injury incidences in seasons 1982 and 2001. Means with standard deviations (SD) and 95\% confidence interval $(95 \% \mathrm{CI})$. 
Table 1. Exclusions and dropouts.

\begin{tabular}{lllllllll}
\hline Season & \multicolumn{2}{l}{ Initial sample } & \multicolumn{2}{l}{ Exclusions } & \multicolumn{2}{l}{ Study sample } & \multicolumn{2}{l}{ Dropouts } \\
\hline & Teams & Players & Teams & Players & Teams & Players & N & $\%$ \\
\hline 1982 & 12 & 180 & 4 & 62 & 8 & 118 & 3 & 2,5 \\
2001 & 14 & 310 & 0 & 0 & 14 & 310 & 31 & 10 \\
\hline
\end{tabular}




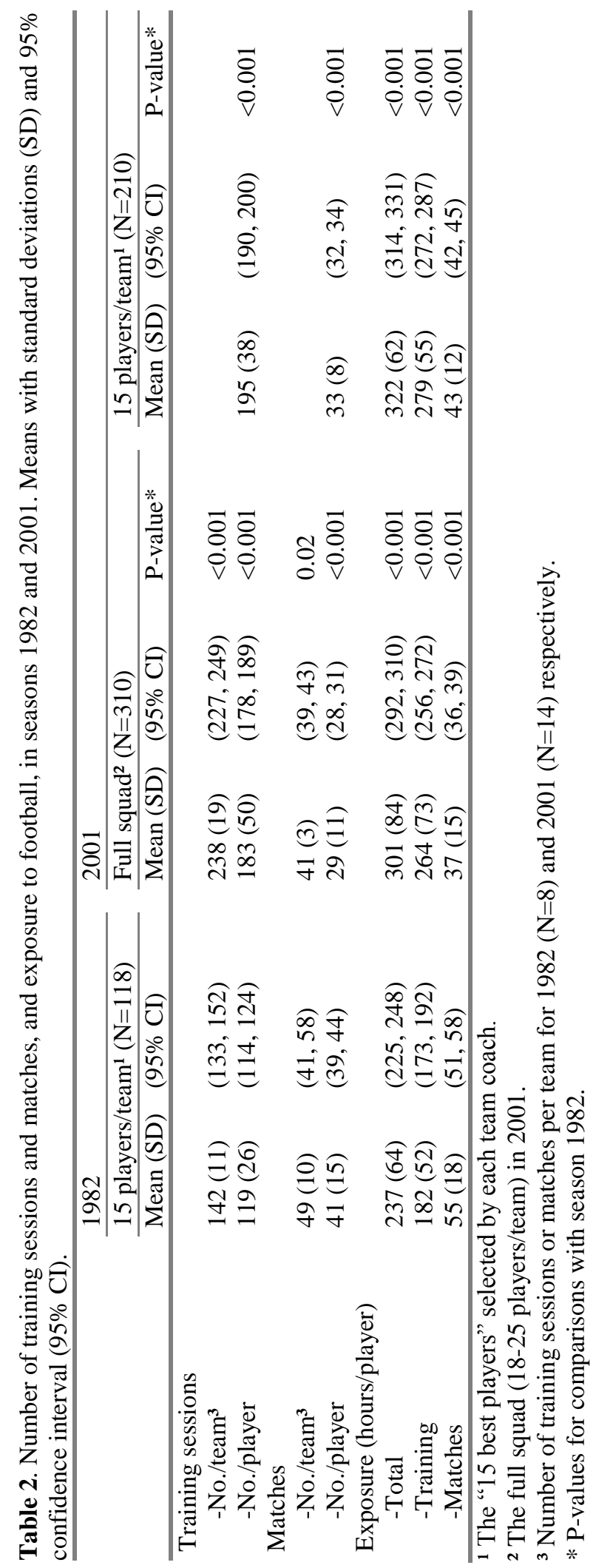


Table 3. Severity of injuries according to absence from training sessions and matches in seasons 1982 and 2001.

\begin{tabular}{|c|c|c|c|c|c|c|c|c|}
\hline & \multicolumn{2}{|c|}{1982} & \multicolumn{6}{|c|}{2001} \\
\hline & \multicolumn{2}{|c|}{15 players/team ${ }^{\mathbf{1}}(\mathrm{N}=118)$} & \multicolumn{3}{|c|}{ Full squad ${ }^{2}(\mathrm{~N}=310)$} & \multicolumn{3}{|c|}{15 players/team $\mathbf{1}(\mathrm{N}=210)$} \\
\hline & $\mathrm{N}$ & $\%$ & $\mathrm{~N}$ & $\%$ & P-value* & $\mathrm{N}$ & $\%$ & P-value* \\
\hline Slight (1-3 days) & 98 & 42 & 233 & 33 & 0.012 & 178 & 33 & 0.022 \\
\hline Minor (4-7 days) & 61 & 26 & 196 & 27 & 0.64 & 149 & 28 & 0.61 \\
\hline Moderate (8-28 days) & 55 & 23 & 219 & 31 & 0.031 & 166 & 31 & 0.035 \\
\hline Major (>28 days) & 22 & 9 & 67 & 9 & 0.98 & 47 & 9 & 0.78 \\
\hline Total & 236 & 100 & 715 & 100 & & 540 & 101 & \\
\hline
\end{tabular}

1 The " 15 best players" selected by each team coach.

2 The full squad (18-25 players/team) in 2001.

${ }^{3}$ Results for totals may not agree with results for individual components due to rounding error.

* P-values for comparisons with season 1982. 


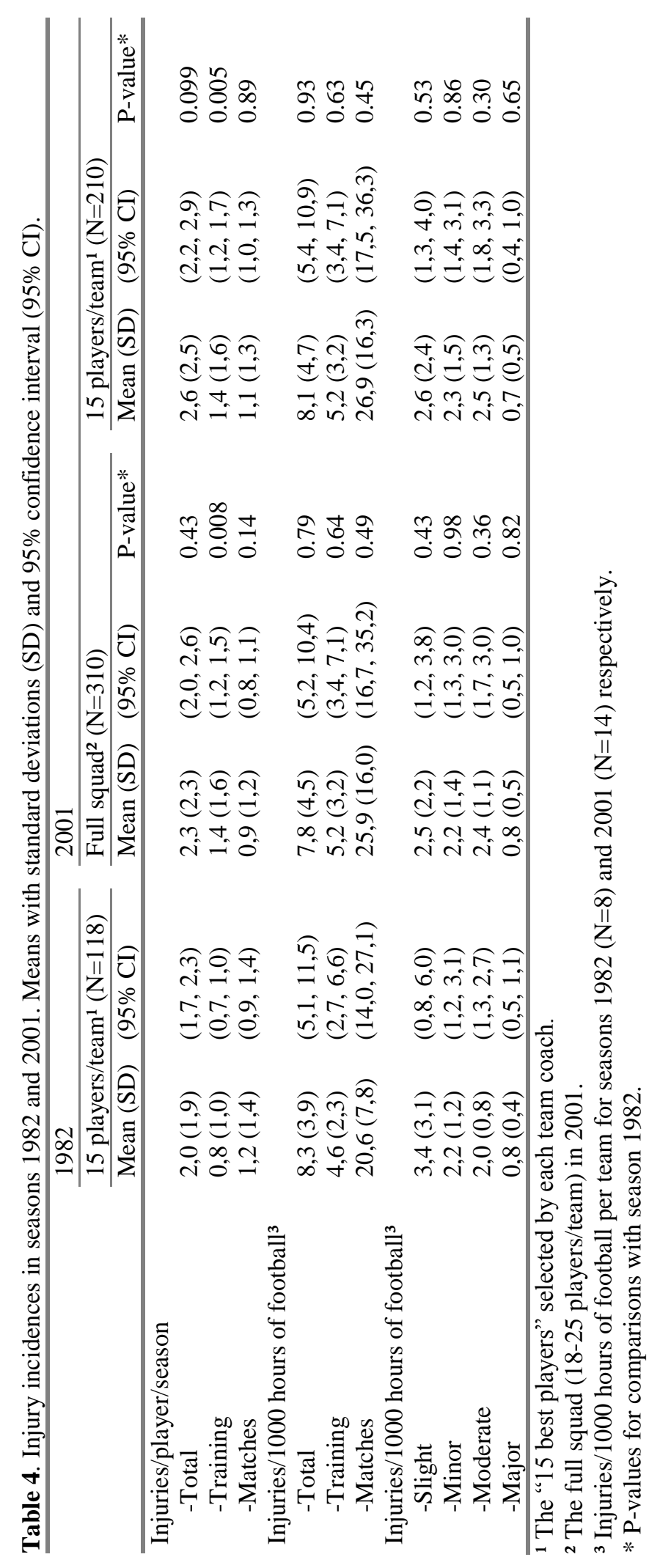

